INNOVATIONS IN PRIMARY CARE

\title{
A 60-Second Survey to Identify Patients' Unmet Social Needs
}

\author{
Sarab R. Reves, MSN, FNP-C'1 Chantal McHenry ${ }^{2}$ \\ Jonathan P. O'Neal ${ }^{1} \quad$ Molly Favour ${ }^{1}$ \\ Martha M. Gonzalez $\quad$ Rebecca S. Etz, PbD \\ 'Virginia Commonwealth University, Department of Family Medi- \\ cine and Population Health, Richmond, Virginia \\ ${ }^{2}$ Virginia Commonwealth University, Department of Internal Medi- \\ cine, Richmond, Virginia
}

Ann Fam Med 2019;17:274. https://doi.org/10.1370/afm.2391.

\section{THE INNOVATION}

The connection between poor social determinants of health and high utilization of health care is well established. ${ }^{1}$ The use of emergency departments for illnesses manageable within the community is common, as are hospitalizations due to preventable disease complications. Patients with poorer social determinants of health tend to have higher 30-day hospital readmission rates. Inspired by Arthur Kaufman's The WellRx Toolkit, we set out to better understand the unmet social needs of our patients to prioritize strategies for providing assistance. ${ }^{2}$ Findings were used to identify partnerships that could connect patients with resources in their communities, potentially reducing patient health burdens and systemic dysfunction.

\section{WHO AND WHERE}

This study was performed by Virginia Commonwealth University's (VCU) Department of Family Medicine and Population Health in collaboration with VCU Health System's (VCUHS) Office of Health Innovation, General Internal Medicine (GIM) inpatient services, and Emergency Department (ED). Patients in GIM and ED answered a 60-second survey during their visits. VCU's Institutional Review Board reviewed this study and determined it to be exempt.

\section{HOW}

In the ED, a research team member approached patients in the waiting room with the 60 -second survey. The survey was a 4 x 6 inch card on which patients identified age, sex, and

Conflicts of interest: autbors report none.

\section{Corresponding author}

Sarah R. Reves, MSN, FNP-C

Virginia Commonwealth University

Department of Family Medicine and Population Health

830 East Main Street

Richmond, VA 23298-0101

Sarah.Reves@vcuhealth.org whether they had needed help within the last 30 days with any of the following: food, housing, utilities, transportation, day care, legal, employment, education, substance abuse, safety, or domestic violence. Options were also provided to write-in "other needs" or choose "no assistance needed". All patients entering the ED during data collection periods were approached and 93\% $(n=508)$ participated. Among GIM services, intake nurses were supplied with the same survey with an additional question regarding whether the patient had been admitted to a hospital in the last 30 days. Nurses were given discretion regarding asking patients whether they were interested in survey participation. Among GIM patients approached during a 4-week period, 75\% ( $n=223)$ participated. Surveys were administered in English and Spanish along with a description of the study and a list of local resources to help patients get assistance for any unmet areas they identified.

\section{LEARNING}

Ambulatory patients are receptive to brief surveys regarding unmet social needs. Little to no patient instruction is required to complete the 15 -item checklist. Ease of survey use by GIM nurses demonstrates low burden on staff and workflow. This survey could easily be used in primary care settings, through front desk paperwork or with rooming staff. Over $60 \%$ of patients reported at least one unmet social need within the last 30 days. In all cases, rates of identified unmet needs were higher among hospitalized patients. Within GIM and ED, we found significant clusters of patients reporting 2 needs (8.1\% GIM; $7.8 \%$ ED) and 3 or more needs (18.4\% GIM; $15.5 \%$ ED). The 3 social needs that appeared to be unmet most often were transportation (26.8\% GIM; $18.4 \% \mathrm{ED})$, food (23.1\% GIM; $16.9 \% \mathrm{ED})$, and housing ( $14.2 \% \mathrm{GIM} ; 12.7 \% \mathrm{ED})$. When these 3 needs were looked at as clusters, transportation and food were commonly linked (33.6\% GIM; 29.2\% ED), as well as housing and food (24.3\% GIM; $26.4 \%$ ED). The triad of transportation, food, and housing followed closely behind (17.8\% GIM; $17.4 \%$ ED). These data were shared with the VCU Office of Health Innovation and have since been used to target relevant community partnerships. Similarly, primary care practices with limited time and resources can prioritize and target community partnerships of most value to their patients once rates of unmet social needs are identified.

For additional information and references, go to http://www. AnnFamMed.org/content/17/3/274/suppI/DC1/.

Submitted October 25, 2018; submitted, revised, January 29, 2019; accepted February 14, 2019.

Key words: primary care; survey; social determinants of health 